Faculty of Education

Te Kura Toi Tangata

Waikato Journal of Education

Te Hautaka Mātauranga o Waikato

Volume 16, Issue 2: 2011 


\section{WAIKATO JOURNAL OF EDUCATION TE HAUTAKA MĀTAURANGA O WAIKATO}

\section{Editors:}

Jane Strachan

Noeline Wright

\author{
Editorial Board: \\ Beverley Bell \\ Bronwen Cowie \\ Deborah Fraser \\ Margie Hohepa \\ Sally Peters \\ Noeline Wright
}

\author{
Margaret Carr \\ Rosemary DeLuca \\ Richard Hill \\ Judy Moreland \\ Clive Pope
}

Waikato Journal of Education is a refereed journal, published annually, based in the Faculty of Education, The University of Waikato, Hamilton, New Zealand. It publishes articles in the broad field of education. For further information visit the WJE website http://edlinked.soe.waikato.ac.nz/research/journal/index.php?id=8

Correspondence and articles for review should be addressed to: Research Manager, Wilf Malcolm Institute of Educational Research, Faculty of Education, The University of Waikato, Private Bag 3105, Hamilton, 3240, New Zealand. Email: wmier@waikato.ac.nz

Business correspondence: Orders, subscription payments and other enquiries should be sent to the Administrator, Waikato Journal of Education, Wilf Malcolm Institute of Educational Research, Faculty of Education, The University of Waikato, Private Bag 3105, Hamilton, 3240, New Zealand, Email: wmier@waikato.ac.nz

Subscriptions: Within NZ \$40; Overseas NZ \$50

Copyright: (C) Faculty of Education, The University of Waikato

Publisher: $\quad$ Faculty of Education, The University of Waikato

Cover design: Donn Ratana

Printed by: Waikato Print

\section{Call for papers}

The Waikato Journal of Education provides an avenue of publication for quality articles on education. This peer-reviewed journal welcomes a range of topics including interdisciplinary, philosophical and applied research approaches.

Submissions are now invited for consideration for publication in the November 2012 issue. Please submit an electronic copy and a separate page with author/s contact details by 30 April 2012 to WMIER Research Manager, Carolyn Jones (cjjones@waikato.ac.nz), Faculty of Education, University of Waikato, Private Bag 3105, Hamilton 3240, New Zealand. 


\section{Waikato Journal of Education}

\section{Te Hautaka Mātauranga o Waikato}

Volume 16, Issue 2: 2011

\section{Special Edition: A teacher education partnership between the Solomon Islands and New Zealand}

Editorial

The Solomon Islands School of Education Partnership: Aspirations, context and design in educational change

Clive McGee and Patricia Rodie

Partnership experiences in developing the Preparation for Tertiary Learning course in the Teachers in Training programme

Roselyn Maneipuri, Immaculate Runialo and Noeline Wright

Making sense of health education in the Solomon Islands

Kirsten Petrie and Mark Tehe

The Solomon Islands mathematics: Pedagogy in transition?

Nigel Calder, John Beuka and Calvin Ngatulu

Taking ownership: The story of a successful partnership for change in a Pacific Island science teacher education setting

Richard Edwards, Solomon Pita and James Porakari

Funds of knowledge: Developing a Diploma in Teaching in Early Childhood Education in the Solomon Islands

Janette Kelly, Joanna Daiwo and Viola Malasa

Weaving a "Hybrid Mat": Samoa meets the Solomons

Barbara Whyte

Sustaining organisational change: Teacher education in the Solomon Islands Jane Strachan, Susanne Maezama and Janine Simi

Exploring factors that influence school planning in community high schools in the Solomon Islands: Principals' perspectives

Samuel Aruhu and David Giles

Experiences of being a leader in Choiseul Province: Opening principals' and deputy principals' contexts of leadership

John Sisiolo and David Giles

Book review 
Waikato Journal of Education

Te Hautaka Mātauranga o

Volume 16 Issue 2: 2011

\title{
Taking ownership: The story of a successful partnership for change in a Pacific Island science teacher education setting
}

\author{
Richard Edwards \\ Faculty of Education \\ University of Waikato

\section{Solomon Pita and James Porakari} \\ School of Education \\ Solomon Islands College of Higher Education
}

\begin{abstract}
This paper explores an example of a partnership approach that appears to be producing sustainable change in a Pacific Islands education setting. The people involved report on the way science education staff from the Solomon Islands School of Education (SOE) and staff from the Faculty of Education University of Waikato $(\mathrm{UOW})$, New Zealand worked together on the redevelopment of undergraduate science education courses for the SOE. Together we sought to identify significant factors supporting the process. The development required significant change and posed a number of challenges yet resulted in local staff producing high quality materials and programmes and taking ownership of ongoing development. More importantly, there was significant personal professional learning in both science education and initial teacher education for local Solomon Islands staff. Factors contributing to the success of the partnership are explored through the perceptions of the participants and include the quality of relationship, mutual respect, emphasis on conceptual agreement when working together, and the involvement of local staff in decision-making.
\end{abstract}

\section{Keywords}

Science education, initial teacher education, Solomon Islands, professional learning, partnership. 


\section{Introduction}

Partnership is increasingly recognised as an integral implementation element of effective aid projects. It is clearly evident in the language of key policy documents such as the Paris Declaration on Aid Effectiveness (OECD, 2005) and the Pacific Aid Effectiveness Principles (Pacific Islands Forum Secretariat, 2007). Partnership involves a shift towards greater ownership by recipient countries of the purpose and implementation of aid funding, working together with donor agencies rather than being passive recipients. This paper explores an example of partnership in the context of a wider Partnership project supporting the redevelopment of teacher education programmes in the Solomon Islands.

In the Pacific, considerable time, effort, and expense have been invested in supporting educational development, yet the results have been mixed in terms of the ability of projects to satisfy the goals and aspirations of the recipient countries and their sustained effectiveness (Coxon \& Munce, 2008; Thaman, 2002). There is a perception that aid delivery has been primarily driven by donor countries motivated by a high degree of self-interest. This is evident for example, in the way aid funding is frequently spent employing consultants from donor countries, particularly on projects that have trade benefits for donor countries. As a result, aid programmes have tended to apply programmes, systems and ideas from outside the recipient countries, thus ignoring the traditional cultures and practices of these Pacific countries. This applies not only in education, but also in other fields, leading to increasing calls for more involvement of Pacific peoples in setting the direction for aid projects.

In 2006, a New Zealand Aid Programme-funded Partnership project was established between the School of Education at the Solomon Islands College of Higher Education (SOE) and the University of Waikato (UOW). From the outset, the Partnership was intended to be flexible and responsive yet with specified outcomes including the development and documentation of revised programmes, initially for teachers already in schools but who had never been inducted into teaching by any formal teacher education programme. A key focus of the Partnership was the establishment of a relationship that emphasised collaborative decision-making while recognising the different roles of the partners. The Partnership ran for four and a half years and involved a series of phases, characterised by problem definition, data collection and analysis, planning, action, and reflective evaluation. This then led to further refinement and the next phase (Alcorn, 2010). While staff worked on programme redevelopment there was an associated redevelopment of institutional systems and frameworks to provide a supporting infrastructure to sustain the improvements.

The School of Education's science department was one of the groups within the Partnership. Their main involvement was in reshaping 12 existing courses that had been focused primarily on teaching science content, into two science education courses. Achieving this required considerable shifts in thinking and practice for SOE staff. In this article we look at how the Partnership approach supported science department staff in doing this and at what made it successful. The concept of partnership was a strong focus but took some time to develop. However, over time it became very effective, and this article focuses on the process of building towards the achievement of the science education goals. 


\section{Theoretical framework}

This section provides a theoretical framework for reporting the stories of the science education participants. It considers factors supporting effective educational change in development aid settings, the concept of partnership with particular reference to the Pacific, and the importance of context.

Educational change is a complex process, taking time to achieve. This is particularly so in the case of educational change supported by development aid. A number of factors that support such change have been identified in the research literature (Gould, 2002). They include the importance of a collaborative approach, the value of having clear goals and a sense of purpose, effective communication, responsiveness to the local context, access to expertise as needed, and acceptance of the need for change. It is also important for the people involved to own the change and be directly involved in decision-making and implementation. This is particularly important if any change is to be sustained over the long term and also if those involved in recipient institutions are to be able to respond dynamically to shifts in context over time.

In the literature associated with development, there has been a shift in language from donor-recipient to donor-partner. This indicates a growing realisation that for aid funding for development projects to be effective in the long term, recipients of the aid need much more control over identifying what is of most benefit to them, and how that aid should be implemented. Achieving this is not an easy process for a number of reasons. Aid donors provide significant amounts of funding and are accordingly reluctant to relinquish control over how that funding is spent, particularly when they want to see that it produces a return on their investment in terms of outcomes-ones they often determine. There is also considerable inertia in aid provision because of the huge size of the industry and the traditions of provision established over many years that have grown out of a colonising period in world affairs. Another factor is the complex tension between local and external expertise. To overcome these issues, there is strong encouragement for a more even partnership approach to aid provision. The New Zealand Aid Programme recognised this policy direction in the establishment of the SOE/UOW partnership and supported the development of a strong relationship, even though at times there were tensions between the desire for partnership and the more traditional demands of specific measurable outcomes.

While much has been written about educational aid projects in the Pacific, there are few reported examples of partnership relationships. One example identified factors that appeared to strengthen a partnership that had been developed to rewrite courses for an undergraduate science education programme in the Solomon Islands (Sanga \& Taylor, 2001). Sanga and Taylor found that a mutual willingness of partners to learn with and from each other was the key ingredient for the partnership and formed the basis of a relationship that was interdependent, mutual and empowering. Another example involved local teachers in the development of a draft Cook Islands technology curriculum (Edwards, 2005). In this case, the quality of the relationship and involvement of local staff in decision-making was beneficial to them in ways beyond the curriculum development itself, including personal professional learning, changes in teaching practice, greater confidence in contributing to school development, and a reduced sense of professional isolation. However, an analysis of the curriculum development process also found that local participants needed access to a broad base of 
knowledge and skills in curriculum development before they could contribute in a meaningful way.

Any development undertaking takes place in a unique context and this can have an impact on the success or otherwise of an aid project. Crossley (2010) made this point clearly when arguing for increased attention in both educational and international development to the place and role of contextual factors, which, he suggests, are too frequently overlooked. He also advocates greater involvement of people from local settings in researching and responding to these contextual influences. A number of authors such as Coxon and Munce (2008), Sanga (2003) and Thaman (2005) have discussed the Pacific context in relation to education development aid, highlighting the point that while there are some distinct similarities across the region, each country has its own unique culture and situation.

In the following discussion, perceptions of science partnership participants form the basis of a consideration of the way the Partnership relationship and context influenced a successful move to local ownership of the educational change process at the centre of the science programme development.

\section{Science department development}

The following comments provide a sense of the context under discussion. An overview of the development process is expressed in Table 1. During the in-country visits, SOE staff worked with specific University of Waikato staff. In between visits, SOE staff worked on mutually agreed tasks. While email was the main form of contact between visits, technical difficulties sometimes limited its effectiveness. There was an urgent need to develop a programme for the large number of untrained teachers teaching in Solomon Islands schools, a legacy of the civil unrest. Once this new programme was established, it became the basis for the subsequent development of the primary teaching diploma programme and the secondary equivalent. As the process continued, SOE staff took increasing responsibility for driving course development.

Table 1. Overview of science department course development activities

\begin{tabular}{|l|l|}
\hline \multicolumn{1}{|c|}{ Time period } & \multicolumn{1}{c|}{ Activities } \\
\hline April 2007-In-country visit & $\begin{array}{l}\text { Initial review of programme. } \\
\text { Developing a common understanding of } \\
\text { effective science education practices relevant } \\
\text { to Solomon Islands schools. }\end{array}$ \\
\hline Between visits & $\begin{array}{l}\text { Initial drafting of core primary science } \\
\text { education course. }\end{array}$ \\
\hline November 2007-In-country visit & $\begin{array}{l}\text { Continued work on science education } \\
\text { understandings. } \\
\text { Development of framework for core science } \\
\text { education course for Teachers in Training } \\
\text { (TIT) and primary diploma students. }\end{array}$ \\
\hline
\end{tabular}




\begin{tabular}{|l|l|}
\hline Between visits & $\begin{array}{l}\text { Completion of course outline and associated } \\
\text { teaching materials for core science course. } \\
\text { Teaching of the course to the first group of } \\
\text { TIT students. }\end{array}$ \\
\hline April 2008_-In-country visit & $\begin{array}{l}\text { Review of and refinement of first TIT course. } \\
\text { Development of second primary science } \\
\text { course for those wanting to specialise in } \\
\text { science. }\end{array}$ \\
\hline Between visits & $\begin{array}{l}\text { Completion of course outline and course } \\
\text { materials for primary science minor. }\end{array}$ \\
\hline August 2008 & Visit of SOE staff to University of Waikato. \\
\hline Between visits & $\begin{array}{l}\text { Ongoing development, including teaching of } \\
\text { primary courses. }\end{array}$ \\
\hline July 2009-In-country visit & $\begin{array}{l}\text { Focus on science within the overall } \\
\text { programme with specific discussion } \\
\text { supporting development of the secondary } \\
\text { courses. }\end{array}$ \\
\hline
\end{tabular}

\section{Methodology}

The data reported here are in the form of a reflective dialogue. The authors collaborated initially on the formulation of a set of question prompts designed to focus attention on aspects of the development process that were perceived to have most influence on its effectiveness. The questions were then circulated for each of those involved to respond to. These responses formed the basis of what is reported below and have been kept as complete as possible in order to maintain the integrity of each person's voice as far as possible. First names are used as identifiers to personalise the responses.

Participants' perceptions have been grouped into the following sections to reflect the agreed questions and to provide some organisation of the responses.

- Key elements of the process - what happened?

- Nature of the relationship-how we worked together

- Success factors - what contributed to successful outcomes?

- Challenges - what constraints were most challenging?

- Outcomes - what were the most important outcomes of the partnership?

\section{Perceptions}

\section{Key elements of the process-what happened?}

In responding to the agreed discussion prompts, participants identified a number of key elements that they remembered as being particularly important.

Solomon (SOE) - We had been planning for this partnership since a review of SICHE (Solomon Islands College of Higher Education) in 2005 and so were keen to get under way with the practical side of the redevelopment. One thing clearly evident about 
the initial stage of the Partnership was the science department members' desire to change. In particular, we realised that our old curriculum, which was content based, was insufficient for the needs of people teaching Solomon Islands children. Also, the curriculum review taking place at the same time was moving from being content-based to outcomes-based. Despite their lack of understanding in developing a learner centred course, the SOE team worked together with the UOW partner to learn and also to make changes to the courses.

James (SOE) - To begin with, everyone knew that we would be redesigning and redeveloping the course for the science department. I myself had no idea where to start and what type of courses we would be designing. We began with an initial discussion of what was expected and did a bit of training in putting together a session. Everyone was involved in the planning stage and in setting up the process to follow and guidelines.

Richard (UOW)-My involvement began with a two-week visit to Honiara to work with the science department to identify what we needed to do to redevelop their courses and to begin work on course outlines and support material. The expected outcomes of my visits were clearly outlined for me before leaving New Zealand. Having worked elsewhere in the Pacific, much of the Honiara experience had a pleasant familiarity yet there were also a number of new aspects to get used to. Trying to get SOE staff together during the first visit to Honiara was very frustrating because at that time they were also fully committed to teaching, preparation, and marking (rectified to some extent for later visits) and the science HOD contracted malaria and was off sick during most of this partnership period.

The second two-week visit to Honiara six months later gave us much more time to work together. Much of this was spent in discussing and developing a consensus about the following: our views about science, the purpose and aims of science education, and what a learner-centred classroom actually meant. As a result, the science department's staff's depth of conceptual understanding was much greater even though this had not yet been translated into the developing course documents, which were nonetheless completed by the agreed time. The first course was taught as part of the Teachers in Training (TIT) programme, established for those teaching in schools who had not yet benefitted from an initial teacher education programme.

We later reviewed the initial development for these TITs and began the development of the rest of the science courses planned for the diploma. In these courses, more of the direction and decision-making were undertaken by SOE science department staff.

\section{Nature of the relationship-how we worked together}

This section presents responses that describe and discuss the nature of the relationship we established and the approaches we adopted in working together.

Solomon (SOE) - When the Partnership was established, it was based on mutual understanding and respect. Our team set out to look at what we had in terms of the old courses and what we wanted the courses to be developed into. Underlying this was our desire to really understand and develop a science teacher education programme that would make science learnable and interesting to the children of the Solomon Islands.

Our way of working was supported by the open and dialogic nature of our partner. We had the opportunity to ask questions and be asked questions so we could map the way forward for the redevelopment. When an idea about a certain aspect of the science 
courses was raised, there was always a collective way of responding to it, either by making a decision on what to do or asking further questions for clarification.

Richard (UOW) - The main focus was on the development of the main science courses. As the department also covered other subject areas such as technology, home economics and health, staff transferred the ideas and principles learnt from the science review to redeveloping these other subjects.

I saw my role as providing professional development in such a way that the science department staff would be able to take on the course and programme development with increasing skill and confidence. This was certainly helped by the way we came to enjoy a professional and collegial relationship.

James (SOE) - We initially just discussed and debated ideas, concepts and models with our counterpart. We also had a bit of training in different ways of seeing things and before our counterpart left we had a work programme to be implemented. We carried out this work programme and we felt ownership of it. We also taught the courses during the Teacher in Training programme, which gave us an opportunity to evaluate the courses and improve them for the diploma programme. Deciding on the readings for the course reader and designing which assessment tasks to do for the courses made us feel that we actually owned the process. I started enjoying each session with our counterpart and learning from each session we had. I also enjoyed and learnt while trying out the new way of teaching and assessing the students. We developed a personal friendship and mutual respect for each other's ideas. We quickly understood each other and worked together to achieve the outcomes of the project.

\section{Success factors-what contributed to successful outcomes?}

In this section we present comments identifying specific factors that participants felt were integral to the success of the science department component of the Partnership.

James (SOE) - Everyone was involved in the planning and review stage. Even though I had no idea where to start or what type of courses we would be designing, we were all together in our desire to change and outline how we would get there. We were involved in designing the overall programme and then the courses themselves. This gave us a sense of the big picture and of being responsible for the changes. We were also given an opportunity to trial the redesigned courses during the Teacher in Training programmes. This allowed us to evaluate the strengths and weaknesses of the courses and improve them for the diploma programme.

Solomon (SOE) - Staff lack of experience was overcome by asking a lot of questions and by the skilful guiding of the partner. Staff belief in the redevelopment was a big factor in our getting involved in the process. This was underpinned by our growing concern that Solomon Islands students fear or lose interest in learning science when they reach secondary school level. As a result we were motivated by our desire to make sure that teachers trained in the SOE will be able to teach science in an interesting way. Another success factor was the way we were able to develop understanding in key areas of education beyond the course development, which was our main objective.

The belief and trust the partner had in us to contribute to and do the job was another crucial factor in our positive attitude and our ability to complete the tasks well. This developed into a personal relationship that continues. It [this relationship] helps us to share ideas, ask questions, and work together as a team freely, even when there were 
difficulties meeting timelines and addressing workload issues. Because of the high level of trust and the cordial working relationship, the science department staff felt that they owned the job and worked hard in getting it done. This continues even now with the former HOD continuing to review and improve course materials. The Partnership produced a sense of true ownership and pride in the redeveloped courses.

Richard (UOW) - Trust in each other was quickly seen to be an important aspect of the work. The trust placed in the SOE staff to complete the practical side of the work was a key factor in their own development and in the longer-term sustainability of what they were doing. It was, however, carefully supported with clear, mutually agreed tasks and timeframes. One of the greatest contributors to success was the willingness and determination of SOE staff to make the changes effectively, even when it meant significant effort on their part.

If people were to be able to contribute in an informed way to the course redevelopment, they needed to reflect on their own understandings of what the courses were aiming to teach and how they could teach them effectively. This provided not only much greater depth conceptually, but also laid the foundation for greater confidence in owning the process. At the time it seemed frustrating that we were not completing the expected tasks during my visits. However, it became apparent that focusing on conceptual development initially and leaving task completion to the team once I had left meant that the course development was more effectively done and that the staff doing the work felt a much greater sense of ownership of it.

James (SOE) - In beginning to design the courses, we discussed ideas about how to develop them and make sure we understood the direction we were taking. We used the weeks working together for training and discussing and throwing in ideas and suggestions and so on. Then we were left alone putting all the ideas together and feeling satisfied that the work was completed.

Solomon (SOE) - an important part of encouraging ownership was the learning that was required because the change and redevelopment of the courses was attached to lecturers' capacity to deliver the changes. This learning was particularly important because science department staff had very little prior experience in either learnercentred teaching or curriculum development.

\section{Challenges-what constraints were most challenging?}

A number of difficulties posed significant challenges to completing the course development. The following comments discuss those considered to be the most significant and how we either found a way around them, or limited their impact.

Solomon (SOE) - There was a definite lack of understanding about developing a learner-centred course but in spite of this, the team worked together with the partner to learn and make the changes to the courses. One of the biggest challenges was letting go of our old programme of 12 content courses and accepting that our courses will now be taught in a two-course arrangement. This reflected the strong subject subculture in the department. While the desire to change was strong, there was some degree of uncertainty about how the changes will help the students learn the content. Another aspect was not really knowing how to put together course materials for the various courses that would encourage learner-centred learning. This is particularly the case in organising practical activities for various programmes. 
James (SOE) - For me, this shift was made more difficult because my background and qualification is in my subject, Physics, and not in science education. As HOD, I felt that I was not contributing much since I am not a science education graduate and that I should have had more knowledge and skills than I had. Also, at the time I was involved in too many things so there was very little time between planning, developing and implementing or for thinking and evaluating the courses we were developing. The new areas we were working in were challenging, including developing student-centred courses and teaching them. We were also concerned because we knew the students we typically have and were not sure that they would take part in the student-centred type of courses we were designing.

Richard (UOW) - For me, the main challenges were mostly procedural At times the slow pace of development meant that things were often not as well set up for completion as I had hoped. This was compounded by the considerable difficulties in maintaining communication between visits as SOE staff had to do more of the work without the level of support I wanted to provide. Interestingly, the challenge of working in a different cultural setting was not very apparent. A number of factors contributed to this: firstly, local staff were able to take responsibility for decision-making; secondly, the initial far-ranging discussions had established a good foundation to work from; and thirdly, my previous experience working in a Pacific country.

\section{Outcomes-what were the most important results of the Partnership?}

The following comments identify key outcomes of the science course development. They indicate the extent to which intended goals were achieved but also highlight other, unintended outcomes that were considered of equal importance.

James (SOE) - I am satisfied with the work that was done but not fully. I felt that I was not contributing much since I am not a science education graduate but someone with a pure science degree. Since I was HOD Science, I felt I needed to have more than the knowledge and skills that I had. After being involved in this partnership, and with the training and discussion with University of Waikato staff, I felt as though I have gone through a postgraduate training in science education. I now have the knowledge, skills and understanding about science education that I lacked. I really enjoyed doing something other than just teaching Physics. The Partnership had a great impact on me as it changed my ideas about the way science should be taught in schools and about the processes and thinking involved in course development. I learnt a lot about more than just how to develop a science education course. I came to understand how different levels of courses are designed, about learning outcomes, and about formative assessment.

It was good to feel we were taking control of the process when we were allowed to complete the first course outlines and prepare the course readings and course materials for ourselves. We taught them and later evaluated them with the counterpart when he came back. During the evaluating sessions we discussed different ways of doing things and were able to make decisions to take it on board and improve it or not.

Solomon (SOE)-The lecturers in the science department felt they owned the job and worked hard in getting it done. This is evident in James who (as HOD) continues to review and improve the various course materials since they were produced. The partnership approach created a true sense of ownership of the courses by the science department. The Partnership has not only redeveloped the science courses but it helped 
us to understand what a learner-centred teaching and learning approach is and also how it could be used to encourage effective learning. It allowed us to understand how to help our trainees become better teachers and to achieve the SOE vision of educating teachers to make a positive difference to learners in Solomon Islands schools.

Richard (UOW) - The most important outcome from my point of view was the confidence and capability that the science department staff developed as demonstrated in the courses and course materials they developed. Being able to work in the Solomon Islands with the people in the science department has broadened my perspective of education in the Pacific and contributed to more effective teaching in my current role at the University of Waikato. I value the relationship developed with Solomon and James and the rest of the department and enjoy our continued interaction. We have maintained contact by email and have started to explore possibilities for collaborative research. We have expressed a desire to continue to work together to improve our science education teaching, but have yet to find a way to do this practically.

\section{Discussion}

The changes that took place during and as a result of the Partnership highlight the effectiveness of the Partnership approach adopted. The outcomes in terms of the Partnership goals were achieved with respect to both the course development and the professional learning of the participants. The existing suite of courses focused on science content has been reshaped into two courses in science education. There has been a shift to a much more student-centred teaching approach. The SOE science department staff are now more confident in their grasp of current research and thinking in science education and are continuing to shift their practice accordingly.

There are strong indications that the changes achieved have been sustained and applied more broadly to continuing development within the School of Education. The approach adopted for the primary course development has been continued by the SOE staff in their development of secondary science courses. Two key people involved in the science department development have now taken on roles at a higher level in the School of Education.

The factors supporting educational change identified earlier were all evident in the comments of participants. In addition, mutual respect and trust was considered important and instrumental in the development of local ownership that appeared to support the sustainability of the changes. Initially the SOE science staff found it difficult to see the nature of the changes required. However, the time taken to establish a collegial relationship and to explore the key concepts was foundational in developing the mutual trust and respect that subsequently enabled the SOE science staff to go on and take increasing responsibility in the development. This in turn led to a growing sense of ownership of the development process and outcomes.

The nature of the Partnership relationship was key to the effectiveness of the Partnership. The focus on establishing a relationship that was open and based on mutual respect laid the foundation for professional engagement with the tasks and with the associated ideas in ways that encouraged debate and personal learning. The relationship relied on a commitment to each other that transcended the immediate needs of the Partnership and resulted in a desire to work together on other projects in the future. The relationship has now changed, maturing into one where each of us interacts more 
independently yet in some ways more collegially, seen for example in the preparation of this article.

The sharing of decision-making shifted the more common power relationships from one where the outside "expert" dominates to one where the SOE staff became increasingly confident in taking ownership of the process and outcomes. Mutual trust was an important element of this. The SOE staff felt trusted when they were left with work to complete and felt a sense of responsibility to get it done. This to some degree moves towards the cultural democracy advocated by Thaman (2009) as it involves the people most immersed in the culture in making key decisions. However the nature of the partnership took this beyond culturally appropriate decision-making to a more critical consideration of the usefulness of ideas from other sources with respect to cultural traditions, expectations and needs.

The context in which the Partnership was undertaken provided a unique set of features to which those involved had to respond. The workload of staff had a significant impact on the availability and involvement of staff, particularly initially. The concurrent redevelopment of the school curriculum and associated resources influenced what needed to be incorporated into the courses. The recognition of the large number of untrained teachers working in Solomon Islands schools led to the development of the Teachers in Training programme. While this put increased pressure on the SOE staff, it also provided an opportunity to trial the courses being developed for the diploma programme. In the science department, several staff members were away overseas on scholarship to complete degrees. As a result, not everyone was involved in the course development and associated professional development.

Such context features clearly had an impact on the way the development evolved. However, the key aspects of the process identified by participants as contributing to success appeared not to be context dependent beyond the nature of the people involved. The emphasis on establishing an effective working relationship, on developing agreed understandings, and on shared decision-making and mutual trust enabled us to respond flexibly to the context in order to achieve what we set out to. This is consistent with the views advocated by Crossley (2010) in that it acknowledges the importance of context and the need for appropriately responsive approaches.

Many of the contextual challenges remain. However, the Partnership as a whole has put considerable emphasis on institutional change and the development of systems and a culture that can resolve issues as they arise and that can maintain the momentum of ongoing review and development. There has been a significant shift in the development of a research culture. While these suggest ownership of the change process and an associated sustainability of the changes, some of the changes in actual teaching practice have not had the same levels of modelling and support provided for the course development. Such changes are important as they represent, in action, the ideas embedded in the course planning and materials. For staff to make these pedagogical changes without significant support will be difficult even with the positive approach and commitment of the staff involved.

\section{Conclusion}

The example of a partnership presented here provides a clear indication of the effectiveness of the approach. There were several factors that appeared to make a 
significant contribution to its effectiveness. These included the establishment of strong personal and professional relationship, a power sharing model that emphasised shared decision-making, spending time exploring and debating core concepts, creating an environment of mutual trust and respect, and the development together of clear frameworks within which to work.

One of the main indications of the effectiveness of the Partnership has been the way each person involved has moved on confidently into new things, building on the work done in redeveloping the primary programme. This is indicative of the sustainability of the changes and appears to come from the way the SOE staff were able to take ownership of both the process and outcomes.

The success of the Partnership described suggests elements of a model that could work well in similar situations in Pacific Island countries and beyond. Its strength lies in the way it enabled the SOE staff to guide development and thereby provide direction for education that was more consistent with their country's needs and aspirations.

\section{References}

Alcorn, N. (2010). Knowledge through a collaborative network: A cross-cultural partnership. Educational Action Research, 18(4), 453.

Coxon, E., \& Munce, K. (2008). The global education agenda and the delivery of aid to Pacific education. Comparative Education, 44(2), 147-165.

Crossley, M. (2010). Context matters in educational research and international development: Learning from the small states experience. Prospects, 40(4), 421429.

Edwards, R. (2005, July). Teachers and curriculum development: Exploring a Cook Islands teacher's experience of technology curriculum development. Paper presented at the Australasian Science Education Research Association (ASERA) conference, Hamilton, New Zealand.

Gould, J. (2002). Maintaining good partnerships: The challenge of long distance relationships. In J. Overton, D. Storey, \& B. Nowak (Eds.), Contesting development: Pathways to better practice; Proceedings of the Third Biennial Conference of the Aotearoa New Zealand International Development Studies Network. Palmerston North, New Zealand: Institute of Development Studies. Massey University.

OECD. (2005). Paris declaration on aid effectiveness. Paris, France: Author.

Pacific Islands Forum Secretariat. (2007). Pacific principles of aid effectiveness. Palau: Author.

Sanga, K. F. (2003). A context-sensitive approach to educational aid. Directions: Journal of Educational Studies, 25(1-2), 28-39.

Sanga, K. F., \& Taylor, L. (2001). Partnership in an aid project: Is it a teacher-learner relationship? Directions: Journal of Educational Studies, 23(1), 42-55.

Thaman, K. H. (2002). Towards cultural democracy in Pacific education. In F.Pene, A. M. Taufe'ulungaki, \& C. Benson (Eds.), Tree of opportunity. Suva, Fiji: Institute Of Education, University of the South Pacific.

Thaman, K. H. (2005). Whose values and what responsibility? Cultural and cognitive democracy in education. Pacific-Asian Education Journal, 17(1), 8-19. 
Thaman, K. H. (2009). Towards cultural democracy in teaching and learning with specific references to Pacific Island nations (PINs). International Journal for the Scholarship of Teaching \& Learning, 3(2), 1-9.

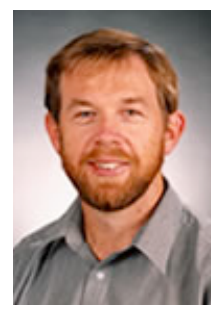

Richard Edwards is involved in initial teacher education in the Faculty of Education, The University of Waikato. His teaching and research interests include science education, technology education, education for sustainability, Pacific education, curriculum development, and indigenous knowledge. His role in the Partnership involved working with the science department in the redevelopment of their programmes, supporting the redevelopment of technology and education for sustainability courses, and facilitating some professional development on course development with Partnership staff.

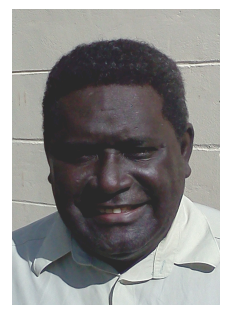

Solomon Pita teaches and coordinates a range of teacher education programmes at the School of Education (SOE), Solomon Islands College of Higher Education (SICHE). He is also involved in research and management. His teaching and research interests include the use of ICT tools in teaching and learning, e-learning, distance and flexible learning and technical and vocational education. His role in the Partnership involved coordination of the teachers in training (TIT) programme, development of science and technology courses, working with the ICT committee, and policy development.

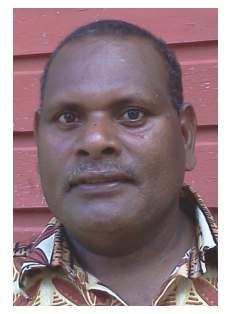

James Porakari has completed a Bachelor of Science and Post Graduate Diploma in physics at The University of the South Pacific, Fiji. He taught senior physics at King George VI National Secondary School before joining the staff of the School of Education in the Solomon Islands. He has been the head of the science department and is currently the Assistant Head of School, Administration. 
